\title{
Experimental and Theoretical Studies of Oxalic Acid Dissociation in Water-Ethanol Solvents
}

\author{
Assouma Dagri Cyrille, Kwa-Koffi Kouassi Edith², Niamien Paulin Marius ${ }^{3}$, Avo Bilé Ehui Bernadette ${ }^{4}$, \\ Aka Kouassi Henri ${ }^{5}$
}

Laboratoire de chimie physique, Université Félix Houphouet Boigny, Cocody-Abidjan

\begin{abstract}
The first and second dissociation constants of oxalic acid were determined using potentiometric and spectrophotometric methods. Measurements were made in water-ethanol solvents of chemical composition in percentage weight of 0, 16.3, and 80. The temperatures ranged from $298 \mathrm{~K}$ to $318 \mathrm{~K}$. The dissociation free enthalpy changes, enthalpy changes and entropy changes were determined and discussed. Furthermore, DFT was used at B3PW91/LanL2DZ level to compute molecular descriptors as $E_{H O M O}, E_{L U M O}$, energy gap $\triangle E_{\text {and }}$ the charge $\delta$ on the oxygen of the hydroxyl group. Those parameters were then used to establish a QSPR model that furnishes $\mathrm{pKa} \mathrm{a}_{1}$ and $\mathrm{pKa} \mathrm{a}_{2}$ values. Experimental and theoretical results were in good agreement.
\end{abstract}

Keywords: Oxalic acid, water-ethanol solvent, thermodynamic dissociation constant, molecular descriptor, QSPR model

\section{Introduction}

The acidity concept has been used in various areas of research and gives us some useful information about the molecular structure of organic molecules. Acid dissociation constants [1] also known as pKa values play a fundamental role in analytical procedures such as acid-base titration, solvent extraction, complex formation and ion transport. It has been shown [2] that acid-base properties affect the toxicity, the chromatographic retention behaviour and the pharmaceutical properties [3] of organic compounds. Much of the theoretical foundation of modern organic chemistry [4] is based on the observation of the effects on acid-base equilibrium of changing molecular structure.

The determination of the dissociation constant of an acid in water- organic oxygen compounds mixtures provides useful data for the theoretical understanding of the ionization process in these media.Several methods are used for the determination of dissociation constants. Potentiometry [5] and UV-VIS absorption spectrometry [6] are useful techniques for the determination of $\mathrm{pKa}$ values, due to their accuracy and reproducibility. Nowadays, some methods for dissociation constants determination, based on separation methods [7], [8] including high performance liquid chromatography (HPLC), capillary electrophoresis (CE) are used.

Recent progress in computational hardware and the development of efficient algorithms has assisted the routine development of molecular quantum mechanical calculations. New semiempirical methods supply realistic quantum chemical calculations in a relatively short computational time frame. Quantum chemical calculations are thus an attractive source of new molecular descriptors which can in principal express all the electronic and geometric properties of molecules and their interactions. Quantum chemistry [9] provides a more accurate and detailed description of electronic effects than empirical methods.

Methods other than thermodynamic cycles are often used to calculate acid dissociation constants. Many publications
[10]-[13] have shown a theoretical relationship between $\mathrm{pKa}$ and the structural property, bond valences methods and bond lengths, $\mathrm{pKa}$ correlations with highest occupied molecular orbital (HOMO) energies and frontier molecular orbitals, and artificial neural networks. The gas-phase free energy calculation [14] is the lowest source of error in $\mathrm{pKa}$ calculations. The problem however, is producing accurate results without using a computationally expensive level of theory. Quantitative structure-activity/property relationship [15] constitute at present the most popular theoretical method for modeling the manner in which biological activity and physical, chemical and technological properties depend on chemical structure of a compound.There are basically two possible ways to create a QSPR model of a feature to be predicted. The first is to create as general a model as possible, with the risk that the accuracy of such a model may not be high. The second approach is to develop more models, each of them being dedicated to a certain class of compounds.

In the work herein, we aim to determine experimentally and theoretically the first and second dissociation constants of oxalic acid which [16] is an important biochemical and industrial compound.The theoretical study is based on the QSPR approach which is used to construct a quantitative model based on a set of the molecular descriptors of the studied compound and the experimental $\mathrm{pKa}$ values. The molecular descriptors parameters calculations were performed in gas phase using Gaussian $03 \mathrm{~W}$ at B3PW91/LanL2DZ level.

\section{Experimental}

\subsection{Materials and Solutions}

All chemicals used were of analytical grade. Oxalic acid was purchased from Merck. It was dehydrated by heating to 100 ${ }^{\circ} \mathrm{C}$ and keeping in a vacuum for 18-20 h. Potassium chloride $(\mathrm{KCl})$ from Merck was dried at $100{ }^{\circ} \mathrm{C}$ for $2 \mathrm{~h}$. Water, with conductivity lower than $10^{-6} \mu \mathrm{S} \mathrm{cm}{ }^{-1}$ was obtained by double distillation. Ethanol from Prolabo was purified by double distillation in presence of sodium. Three kinds of 


\section{International Journal of Science and Research (IJSR) \\ ISSN (Online): 2319-7064}

Index Copernicus Value (2013): 6.14 | Impact Factor (2014): 5.611

water-ethanol solvents of composition in percentage weight of ethanol 0,16.3and 80 were used. Disodium oxalate from Merck was dried at $125{ }^{\circ} \mathrm{C}$ for more than $4 \mathrm{~h}$. Monosodium oxalate salt was prepared by adding calculated quantities of sodium bicarbonate solution to known weights of pure oxalic acid, evaporating the solution to dryness on a steam bath, and recrystallizing the product from $95 \%$ alcohol. The salt obtained was dried at $110-120^{\circ} \mathrm{C}$ for at least $2 \mathrm{~h}$. These salts were kept in vacuum desiccators until required.

Sodium hydroxide, potassium hydroxide, hydrochloric acid, formic acid and dichloroacetic acid were purchased from Merck. Stocks solutions of $\mathrm{NaOH}$ and $\mathrm{HCl}$ at the same concentration $2 \times 10^{-2} \mathrm{M}$ were made. Two sets of buffer solutions were used: (a) dichloroacetic acid-potassium hydroxide $2 \times 10^{-3} \mathrm{M}$, covering the $\mathrm{pH}$ range from 1 to 3 and (b) formic acid-potassium hydroxide $2 \times 10^{-3} \mathrm{M}$, covering the $\mathrm{pH}$ range from 3 to 6 . Fivebuffer solutions were prepared with different ionic strength, using water-ethanol mixtures of composition in percentage weight of $0,16.3$ and 80 . A stock solution of $2 \times 10^{-3} \mathrm{M}$ of oxalic acid was prepared by dissolving an accurately weighed amount of the pure reagent in double distilled water.

\subsection{Apparatus and Procedures}

\subsubsection{Potentiometric method}

Potentiometric determination of $\mathrm{p} K_{a 1}$ and $\mathrm{p} K_{a 2}$ values of the oxalic acid were obtained with respective measurements of $\mathrm{pH}$ of the cells: cell 1: $\mathrm{Hg}, \mathrm{Hg}_{2} \mathrm{Cl}_{2} / \mathrm{KCl}$ saturated // $A \mathrm{H}_{2}$ $(m), A \mathrm{HNa}(m)$ / glass electrode and cell 2: $\mathrm{Hg}, \mathrm{Hg}_{2} \mathrm{Cl}_{2} / \mathrm{KCl}$ saturated // $A \mathrm{HNa}(m), A \mathrm{Na}_{2}(m) /$ glass electrode; where $A \mathrm{H}_{2}, A \mathrm{HNa}, A \mathrm{Na}_{2}$ are respectively oxalic acid, mono- and disodium salts of the oxalic acid. $m$ is the molal concentration of these reagents. These $\mathrm{pHs}$ were measured with a $\mathrm{pH}$-meter Tacussel-Research which is combined with a glass and calomel-saturated electrodes. The accuracy of the instrument was $\pm 0.01 \mathrm{pH}$ unit. The combined electrode system was stored in water when it is not used and soaked for 15-20 min in water-ethanol mixture before $\mathrm{pH}$ measurements. The measurements of the $\mathrm{pH}$ were carried out at the desired temperatures $(298,303,308,313$, and 318 $\mathrm{K})$. The temperature was controlled by water circulation through the jacket, from thermostat and maintained within \pm $0.1 \mathrm{~K}$.

For each of the three kinds of solvents, five equimolal solutions in acid and in alkaline salt of this acid of different concentrations raging from $3 \times 10^{-3}$ to $16 \times 10^{-3} \mathrm{M}$ were prepared in order to obtain buffer mixtures. The concentrations of these solutions were expressed in molality by weighing of chemicals at $10^{-4}$ unit of weight. The calibration of the electrodes was made with the buffers of Bates [17] at the desired temperatures $(298,303,308,313$ and $318 \mathrm{~K}$ ) and then the $\mathrm{pH}$ of these buffer solutions were measured with cell 1 and cell 2 and with a $\mathrm{pH}$-meter Tacussel Research.

Triplicate $\mathrm{pH}$ measurements of each system was performed. In all instances, the $\mathrm{pH}$-meter gave stable and reproducible $\mathrm{pH}$ values within $5 \mathrm{~min}$. The $\mathrm{pH}$ values obtained allow calculation of $\mathrm{p} K a_{1}$ and $\mathrm{p} K a_{2}$ values. The $\mathrm{p} K a_{1}$ value of oxalic acid was determined with buffer solutions made with oxalic acid and monosodium oxalate salt. As for $\mathrm{pKa}$ values, they were determined by realising buffer solutions formed with mono- and disodium salts of the oxalic acid.

\subsubsection{Spectrophotometric method}

For $\mathrm{pKa} a_{1}$ value's determination, five standards solutions were prepared adding $1 \mathrm{~mL}$ of stock solution of oxalic acid $2 \times 10^{-3} \mathrm{M}$ to $100 \mathrm{~mL}$ of five dichloroacetic acid-potassium hydroxide buffers ( $\mathrm{pH}$ between 1 and 3 ) with water as solvent. The same procedure was used to prepare two standards solutions with stocks solutions of $\mathrm{NaOH}$ and $\mathrm{HCl}$. The analytic concentration of these seven standard solutions was $2 \times 10^{-5} \mathrm{M}$. Series of similar standard solutions were prepared using dichloroacetic acid-potassium hydroxide buffers at the same $\mathrm{pH}$ interval and stocks solutions of $\mathrm{NaOH}$ and $\mathrm{HCl}$ with the five others water-ethanol mixtures of composition in weight of 16.3 and 80 . All these series of standard solutions were placed in UV cells, hermetically closed and the temperature was maintained at $298 \mathrm{~K}$ for 15 min. After that, the UVVisible spectra were recorder on a Jasco V 530 UV-Visible double beam spectrophotometer, between 250 and $310 \mathrm{~nm}$. The corresponding absorbance values were determined at $278 \mathrm{~nm}$. For $\mathrm{pKa} a_{2}$ value $\mathrm{s}$ determination, the procedure described for $\mathrm{pKa} a_{1}$ was followed. In this case, formic acid-potassium hydroxide buffers ( $\mathrm{pH}$ between 3 and 6) were used. UV-Visible spectra were recorded between 200 and $320 \mathrm{~nm}$. The absorbance values were determined at $248 \mathrm{~nm}$.

\section{Results and Discussion}

\subsection{Thermodynamic functions}

As a diacid, the dissociation of oxalic acid can be considered as presented in the above scheme:

$\mathrm{H}_{2} \mathrm{~A} \rightleftarrows \mathrm{HA}^{-}+\mathrm{H}^{+}: \mathrm{K}_{a 1}$

$A H^{-} \rightleftarrows A^{2-}+H^{+}: K_{a 2}$

The dissociation constants are given by:

$$
\begin{gathered}
p K_{a 1}=p H-\log \frac{m_{\mathrm{AH}^{-}}}{m_{\mathrm{H}_{2} \mathrm{~A}}}-\log \gamma_{\mathrm{HA}^{-}} \\
p K_{\mathrm{a} 2}=p H-\log \frac{\mathrm{m}_{\mathrm{A}^{2-}}}{m_{\mathrm{HA}^{-}}}-\log \frac{Y_{\mathrm{A}^{2-}}}{\mathrm{YHA}^{-}} \\
p H=-\log a_{\mathrm{H}^{+}}
\end{gathered}
$$

Where:

$a_{H^{+}}, m_{H_{2} A}, m_{H A^{-}}$and $m_{A^{2-}}$ are respectively hydrogen cation activity and molal concentration of $\mathrm{H}_{2} \mathrm{~A}, \mathrm{HA}^{-}$and $\mathrm{A}^{2-} . \gamma_{H A}$ and $\gamma_{A^{2}}$ are the activity coefficients of ionized species calculated from Debye-Hückel's theory according to equation:

$$
-\log \gamma_{i}=\frac{s^{f} z_{i}^{2} \sqrt{I}}{1+A^{y} a_{1} \sqrt{I}}
$$

With:

$$
\begin{aligned}
I & =\frac{1}{2} \sum_{\mathrm{i}} m_{\mathrm{i}} Z_{\mathrm{i}}^{2} \\
S^{v} & =\frac{1.824510^{6}}{(8 T)^{3 / 2}} \\
A^{s} & =\frac{50.29}{(8 T)^{1 / 2}}
\end{aligned}
$$

In relations (4) and (5), $I$ is the ionization strength, $Z_{i}$ is the charge of the ion i, $S^{s}$ and $A^{v}$ are coefficients depending on the values of dielectric constant $\varepsilon$ and temperature; $a_{i}$ is the 


\section{International Journal of Science and Research (IJSR) \\ ISSN (Online): 2319-7064 \\ Index Copernicus Value (2013): 6.14 | Impact Factor (2014): 5.611}

so called ionic parameter [18], [19] which characterizes the average of approach distant of the solvated ions supposed to be $5 \hat{A} \cdot S^{s}$ and $A^{v}$ were computed using equations (6) and (7). In aqueous solution at $T=298 K, \quad S^{s}=0.51$ and $A^{v}=0.329$

Combining the above equations one can compute the first and second dissociation constant of oxalic acid using the following equations:

$p K_{a 1}=p H+\frac{s^{y} z_{i}^{2} \sqrt{I}}{1+A^{y} a_{1} \sqrt{I}}$

$p K_{a 2}=p H+\frac{a s^{\prime} z_{i}^{2} \sqrt{I}}{1+A^{v} a_{i} \sqrt{I}}$

The plots of $p K_{a 1}$ and $p K_{a 2}$ versus $\sqrt{I}$ for different temperature in aqueous solutions at $\mathrm{T}=298 \mathrm{~K}$ are giving by Figure 1.

The plots yield straight lines. This is in full agreement with the Debye Hückel equation. First and second dissociation constants (at $\mathrm{I}=0$ ) were determining using linear regression analysis.
The values of $\mathrm{pKa}_{1}$ and $\mathrm{pKa}_{2}$ at different temperatures and different ionic strengths are included in Table 1.

Mean constants values of the hydroorganic solvents are listed in table 2 .

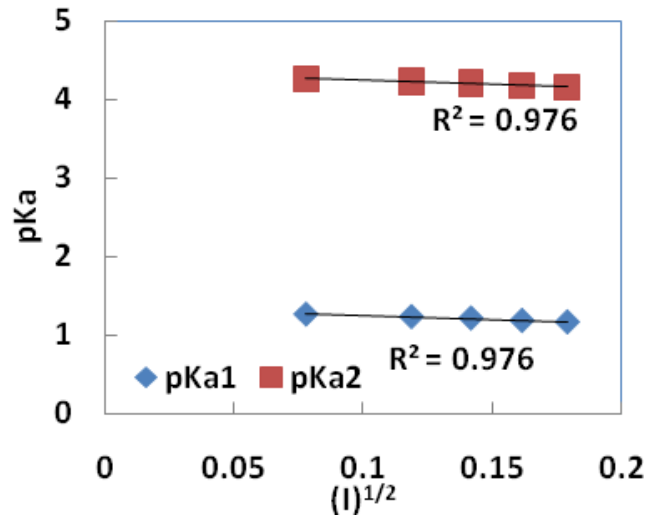

Figure 1: Plots of $\mathrm{pKa}_{1}$ and $\mathrm{pKa}_{2}$ values of oxalic acid versus $\sqrt{I}$ in water at $\mathrm{T}=298 \mathrm{~K}$.

Table 1: Potentiometric determination of $\mathrm{pKa}_{1}$ and $\mathrm{pKa}_{2}$ at different temperatures and ionic strengths for oxalic acid in mixed solvents of different weights in percentage of ethanol

\begin{tabular}{|c|c|c|c|c|c|c|c|c|c|c|c|c|}
\hline \multirow[b]{3}{*}{$\mathrm{Wt}(\%)$} & \multirow{3}{*}{\multicolumn{2}{|c|}{$\mathrm{I}\left(\mathrm{mol}^{\left.-\mathrm{dm}^{-3}\right)}\right.$}} & \multicolumn{10}{|c|}{$\mathrm{T}(\mathrm{K})$} \\
\hline & & & \multicolumn{2}{|c|}{298} & \multicolumn{2}{|c|}{303} & \multicolumn{2}{|c|}{308} & \multicolumn{2}{|c|}{313} & \multicolumn{2}{|c|}{318} \\
\hline & & & $\mathrm{pKa}_{1}$ & $\mathrm{pKa}_{2}$ & $\mathrm{pKa}_{1}$ & $\mathrm{pKa}_{2}$ & $\mathrm{pKa}_{1}$ & $\mathrm{pKa}_{2}$ & $\mathrm{pKa}_{1}$ & $\mathrm{pKa}_{2}$ & $\mathrm{pKa}_{1}$ & $\mathrm{pKa}_{2}$ \\
\hline \multirow{5}{*}{0} & 0.032 & 0.064 & 1.16 & 4.16 & 1.15 & 4.20 & 1.14 & 4.24 & 1.13 & 4.28 & 1.12 & 4.32 \\
\hline & 0.026 & 0.052 & 1.18 & 4.18 & 1.17 & 4.22 & 1.16 & 4.26 & 1.15 & 4.30 & 1.14 & 4.34 \\
\hline & 0.020 & 0.040 & 1.21 & 4.21 & 1.20 & 4.25 & 1.19 & 4.29 & 1.18 & 4.33 & 1.17 & 4.37 \\
\hline & 0.014 & 0.028 & 1.23 & 4.23 & 1.22 & 4.27 & 1.21 & 4.31 & 1.20 & 4.35 & 1.19 & 4.39 \\
\hline & 0.006 & 0.012 & 1.26 & 4.26 & 1.25 & 4.30 & 1.24 & 4.34 & 1.23 & 4.38 & 1.22 & 4.42 \\
\hline \multirow{5}{*}{16.3} & 0.032 & 0.064 & 1.50 & 4.74 & 1.49 & 4.78 & 1.47 & 4.83 & 1.46 & 4.88 & 1.44 & 4.92 \\
\hline & 0.026 & 0.052 & 1.53 & 4.76 & 1.52 & 4.80 & 1.50 & 4.85 & 1.49 & 4.90 & 1.47 & 4.94 \\
\hline & 0.020 & 0.040 & 1.56 & 4.79 & 1.55 & 4.83 & 1.53 & 4.88 & 1.52 & 4.93 & 1.50 & 4.97 \\
\hline & 0.014 & 0.028 & 1.59 & 4.81 & 1.58 & 4.85 & 1.56 & 4.90 & 1.55 & 4.95 & 1.53 & 4.99 \\
\hline & 0.006 & 0.012 & 1.63 & 4.84 & 1.62 & 4.88 & 1.60 & 4.93 & 1.59 & 4.98 & 1.57 & 5.02 \\
\hline \multirow{5}{*}{80} & 0.032 & 0.064 & 2.87 & 7.04 & 2.84 & 7.12 & 2.81 & 7.18 & 2.78 & 7.24 & 2.76 & 7.30 \\
\hline & 0.026 & 0.052 & 2.89 & 7.06 & 2.86 & 7.14 & 2.83 & 7.20 & 2.80 & 7.26 & 2.78 & 7.32 \\
\hline & 0.020 & 0.040 & 2.92 & 7.09 & 2.89 & 7.17 & 2.86 & 7.23 & 2.83 & 7.29 & 2.81 & 7.35 \\
\hline & 0.014 & 0.028 & 2.94 & 7.11 & 2.91 & 7.19 & 2.88 & 7.25 & 2.85 & 7.31 & 2.83 & 7.37 \\
\hline & 0.006 & 0.012 & 2.97 & 7.14 & 2.94 & 7.22 & 2.91 & 7.28 & 2.88 & 7.34 & 2.86 & 7.40 \\
\hline
\end{tabular}

Table 2: Mean values of dielectric constant $\varepsilon$ and that of coefficients $S^{s}$ and $A^{s}$.

\begin{tabular}{|c|c|c|c|}
\cline { 2 - 4 } \multicolumn{1}{c|}{} & \multicolumn{3}{c|}{ Pourcentage weight of ethanol } \\
\cline { 2 - 4 } \multicolumn{1}{c|}{} & 0 & 16.3 & 80 \\
\hline$\varepsilon$ & 78.5 & 69.70 & 35.30 \\
\hline$S^{s}$ & 0.5099 & 0.6095 & 1.6911 \\
\hline$A^{s}$ & 0.3288 & 0.3489 & 0.4903 \\
\hline
\end{tabular}

In the case of the spectrophotometric measurements the relations that give $p K a_{1}$ and $p K a_{2}$ are:

$$
p K a_{1}=p H-\log \frac{A_{H_{2} A^{-} A}}{A-A_{H A^{-}}}-\log \gamma_{H A^{-}}
$$

$$
p K a_{2}=p H-\log \frac{A_{H A^{-}-A}}{A-A_{A^{2}-}}-\log \frac{Y_{A^{2}-}}{Y_{H A^{-}}}
$$

Where:

$A$ is the absorbance of various acid species in buffer solutions at the given $\mathrm{pH}$ values, $A_{\mathrm{H}_{2} A}$ is the absorbance of the acid in the neutral form, $A_{H A^{-}}$et $A_{A^{2-}}$ are the absorbanceof the mono-anion and the di-anion species (of the acid $\mathrm{HA}^{-}$and $\mathrm{A}^{2-}$ ). The observed absorbance and the computed $p K a_{1}$ and $p K a_{2}$ of oxalic acid at $298 \mathrm{~K}$ are listed I table 3 . 


\section{International Journal of Science and Research (IJSR) \\ ISSN (Online): 2319-7064}

Index Copernicus Value (2013): 6.14 | Impact Factor (2014): 5.611

Table 3: Absorbance and $p K a_{1}$ and $p K a_{2}$ values of oxalic acid at $298 \mathrm{~K}$

\begin{tabular}{|c|c|c|c|c|c|c|c|}
\hline$A^{\square}$ & $-\log \frac{A_{H_{2} A}-A}{A-A_{H A^{-}}}$ & $p H^{a}$ & $p K a_{1}$ & $A^{b}$ & $-\log \frac{A_{H A^{-}-A}}{A-A_{A^{2-}}}$ & $p H^{b}$ & $p K a_{2}$ \\
\hline 0.2748 & 0.2003 & 1.04 & 1.28 & 0.0948 & 0.5723 & 3.57 & 4.27 \\
\hline 0.2651 & 0.1421 & 1.11 & 1.29 & 0.0909 & 0.5368 & 3.61 & 4.27 \\
\hline 0.2519 & 0.0647 & 1.17 & 1.27 & 0.0900 & 0.5027 & 3.65 & 4.28 \\
\hline 0.2449 & 0.0242 & 1.22 & 1.28 & 0.0885 & 0.4489 & 3.69 & 4.26 \\
\hline 0.2353 & -0.0311 & 1.27 & 1.28 & 0.0873 & 0.4079 & 3.75 & 4.28 \\
\hline
\end{tabular}

${ }^{a} A_{H 2 A}=0.5569, A_{H A}{ }^{-}=0.1399, \lambda=278 \mathrm{~nm}, \quad-\log \left(\gamma_{H A}\right)=$ 0.0428

${ }^{b} A_{H A}{ }^{-}=0.1054, A_{A}{ }^{2-}=0.0410, \lambda=248 \mathrm{~nm},-\log \left(\gamma_{A}{ }^{2-} / \gamma_{H A-}\right)$ $=0.1287$

Examining tables 1 and 2, one can see that $\mathrm{pKa}_{1}$ decreases with increasing temperature whereas we note an increasing trend for $\mathrm{pKa}_{2}$. These behaviors could be explained by a strong acid character of oxalic acid and a weak acid character for its conjugated ion, hydrogenooxalate ion (scheme below).

$\mathrm{H}_{2} \mathrm{C}_{2} \mathrm{O}_{4} \rightleftarrows \mathrm{HC}_{2} \mathrm{O}_{4}^{-}+\mathrm{H}^{+}: p K a_{1}$

$\mathrm{HC}_{2} \mathrm{O}_{4}^{-} \rightleftarrows \mathrm{C}_{2} \mathrm{O}_{4}^{2-}+\mathrm{H}^{+}: \quad \mathrm{pKa}_{2}$

On the whole, the $p K a$ values depend on that of the dielectric constant $\varepsilon: p K a$ increases with decreasing value of the dielectric constant, meaning that the dissociation of the acid depends on the extent of the quantity of modifier (ethanol) in the mixture. This statement [20], [21] has been reported in the literature. The mean values of $\mathrm{pKa}_{1}(1.28 \pm 0.02)$ and $\mathrm{pKa}_{2} \quad(4.27 \pm 0.02)$ obtained for spectrophotometric measurements at $298 \mathrm{~K}$ (table 3) are more or less identical to those obtained using the potentiometric method. The thermodynamic quantities $\left(\Delta G^{0}{ }_{x} \Delta H^{0}{ }_{n} \Delta S^{0}\right)$ associated with the dissociation of oxalic acid at different values of dielectric constants have been determined using the following equation:

$$
\Delta G^{0}=-R T \ln K
$$

This equation can be written as follows:

$$
\Delta G^{0}=2.303 R T p K
$$

$\mathrm{R}$ is the perfect gas constant and $\mathrm{T}$ is the temperature in Kelvin. Both the standard enthalpy $\left(\Delta H^{0}\right)$ and entropy $\left(\Delta S^{0}\right)$ changes are correlated with the Gibb's free energy change by the relation:

$$
\Delta G^{0}=\Delta H^{0}-T \Delta S^{0}
$$

Figures 2 and 3 give the plots of $\Delta G^{\mathbb{0}}$ versus the temperature. The values offree standard enthalpy changes $\left(\Delta G^{0}\right)$, standard enthalpy changes $\left(\Delta H^{0}\right)$ and standard entropy changes $\left(\Delta S^{\circ}\right)$ for the first and second dissociation at different percentage in weight of ethanol and different temperatures are listed in table 4.

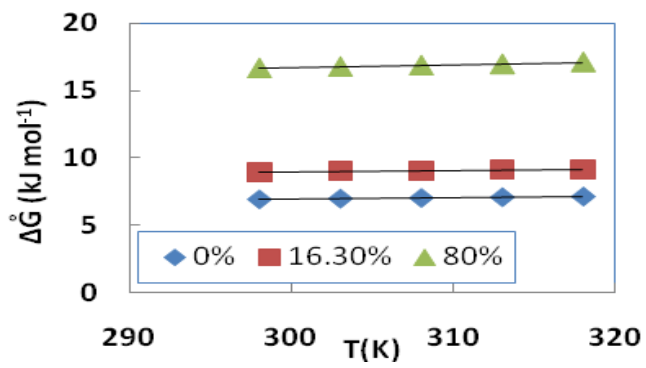

Figure 2: Free standard enthalpy changes versus temperature for the first dissociation.

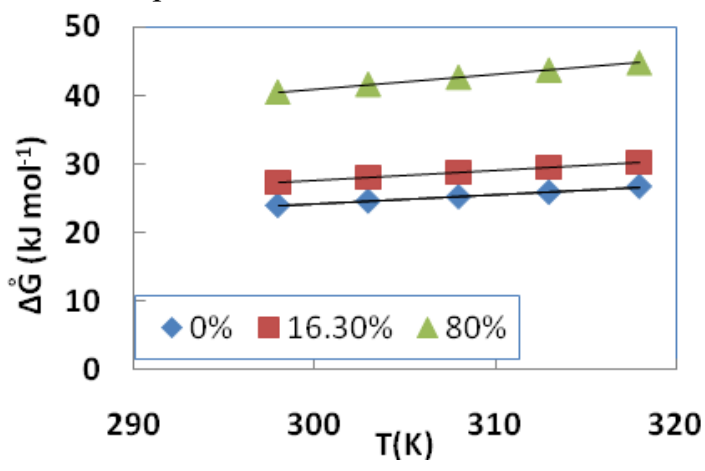

Figure 3: Free standard enthalpy changes versus temperature for the second dissociation. 


\section{International Journal of Science and Research (IJSR) \\ ISSN (Online): 2319-7064}

Index Copernicus Value (2013): 6.14 | Impact Factor (2014): 5.611

Table 4: Standard thermodynamic functions for the first and second dissociation processes of oxalic acid

\begin{tabular}{|c|c|c|c|c|c|c|c|}
\hline \multicolumn{2}{|c|}{ 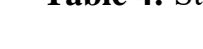 } & \multicolumn{3}{|c|}{ First dissociation } & \multicolumn{3}{|c|}{ Second dissociation } \\
\hline $\begin{array}{l}\mathrm{W}_{\mathrm{t}} \\
(\%)\end{array}$ & $\mathrm{T}(\mathrm{K})$ & $\begin{array}{l}\Delta G^{0} \\
\left(\mathrm{~kJ} \cdot \mathrm{mol}^{-1}\right)\end{array}$ & $\begin{array}{l}\Delta H^{0} \\
\left(\mathrm{~kJ} \cdot \mathrm{mol}^{-1}\right)\end{array}$ & $\begin{array}{l}\Delta S^{0} \\
\left(J \cdot \mathrm{mol}^{-1} K^{-1}\right)\end{array}$ & $\begin{array}{l}\Delta G^{0} \\
\left(\mathrm{~kJ} \cdot \mathrm{mol}^{-1}\right)\end{array}$ & $\begin{array}{l}\Delta H^{\mathbb{0}} \\
\left(\mathrm{kJ} \cdot \mathrm{mol}^{-1}\right)\end{array}$ & $\begin{array}{l}\Delta S^{0} \\
\left(J \cdot m^{-1} K^{-1}\right)\end{array}$ \\
\hline \multirow{5}{*}{0} & 298 & 6.904 & \multirow{5}{*}{3.63} & \multirow{5}{*}{-11.00} & 24.022 & \multirow{5}{*}{-16.70} & \multirow{5}{*}{-136.6} \\
\hline & 303 & 6.962 & & & 24.657 & & \\
\hline & 308 & 7.018 & & & 25.299 & & \\
\hline & 313 & 7.072 & & & 25.950 & & \\
\hline & 318 & 7.124 & & & 26.791 & & \\
\hline \multirow{5}{*}{16.3} & 298 & 8.912 & \multirow{5}{*}{5.45} & \multirow{5}{*}{-11.70} & 27.331 & \multirow{5}{*}{-16.73} & \multirow{5}{*}{-147.7} \\
\hline & 303 & 9.004 & & & 28.022 & & \\
\hline & 308 & 9.035 & & & 28.779 & & \\
\hline & 313 & 9.121 & & & 29.546 & & \\
\hline & 318 & 9.145 & & & 30.261 & & \\
\hline \multirow{5}{*}{80.0} & 298 & 16.650 & \multirow{5}{*}{10.16} & \multirow{5}{*}{-21.70} & 40.454 & \multirow{5}{*}{-23.22} & \multirow{5}{*}{-213.8} \\
\hline & 303 & 16.755 & & & 41.597 & & \\
\hline & 308 & 16.854 & & & 42.638 & & \\
\hline & 313 & 16.948 & & & 43.689 & & \\
\hline & 318 & 17.097 & & & 44.753 & & \\
\hline
\end{tabular}

The positive sign of standard free enthalpy changes for both first and second dissociations denotes that these processes are not spontaneous. It can be seen

in table 4 that the enthalpy changes for the first dissociation are positive showing an endothermic process while that of the second dissociation are negative implying an exothermic process. The negative values of entropy changes point to increased ordering due to an association. It is obvious that as the composition of organic solvent increases, the $\mathrm{pKa}$ values also increase. The dielectric constant of a solvent is the measure of a solvent's efficiency to separate oppositely charges ions. According to Coulomb's law the attraction forces ( $F$, in Newton) between two ions charged with $q^{-}$ and $q^{+}$(in coulombs) separated by distance $r$ (in meter) is:

$$
F=8.988 \times 10^{9} q^{2} / \varepsilon r^{2}
$$

Where $\varepsilon$ is the dielectric constant of the solvent. The attractive force [21] is inversely proportional to the dielectric constant. The larger the value of the dielectric constant, the smaller the attraction forces between the two ions $\left(\mathrm{H}^{+}\right.$and $\mathrm{HC}_{2} \mathrm{O}_{4}^{-}$for the first dissociation) and thus the larger acidity constant Ka values and lower pKa values. The dielectric constant of water and ethanol are 78.5 and 24.5 respectively. With an increase of ethanol concentration, the dielectric constant value of the solvent [21] will decrease resulting in a decrease of acidity constant or increase in $\mathrm{pKa}$ values. When the ionization of an acid gives a net increase of ions, a decrease in the dielectric constant of the solvent should be accompanied by a decrease in the protonation constant (increase of $\mathrm{pKa}$ ) of a weak acid dissolved in it. A solvent of low dielectric constant increases the electrostatic forces between the ions and facilitates the formation of molecular species, and should increase $\mathrm{pKa}$.

For the second dissociation process one can observed that the values of the standard enthalpy changes $\Delta H^{\mathbb{0}}$ decrease with increasing organic content of the solvent mixtures, suggesting that the second dissociation process becomes increasingly exothermic. The standard entropy changes are large and negative showing an ordering trend.

\subsection{Computational Details}

Molecular descriptors have been computed using density functional theory DFT at B3PW91 (Becke 3 parameters Perdew/Wang 91) level with LanL2DZ basis set. The calculations have been performed using Gaussian $03 \mathrm{~W}$ package. The descriptors were computed after a geometry optimization of the molecule. The descriptors in concern are the HOMO energy $E_{\text {Howo }}$ the LUMO energy $E_{\text {Lumo }_{a}}$ the energy gap $\Delta E$, the dipole moment $\mu$ and the charge $\delta$ on the oxygen of the hydroxyl group. Table 5 gives the quantum parameters of the oxalic acid.

Table 5: Computed molecular descriptor of oxalic acid using B3PW91/LanL2DZ

\begin{tabular}{|c|c|c|c|c|}
\hline$E_{\text {HOMo }}(\mathrm{eV})$ & $E_{\text {LUMo }}(\mathrm{eV})$ & $\Delta E(\mathrm{eV})$ & $\mu(\mathrm{D})$ & $\delta(e)$ \\
\hline-8.1962 & -2.9310 & 5.265 & 0 & -0.4272 \\
\hline
\end{tabular}

\subsection{QSPR Models}

QSPR models with three descriptors were constructed using five sets of descriptors. The general equation of the model is given by the multiple linear regression equation below:

$\mathrm{C}$ and E). The solutions of these systems were computed using Excel 2007 program. The selection of appropriate descriptors that are significantly related to the property of interest is very important.

$$
p K_{a}=A D_{1}+B D_{2}+C D_{a}+E
$$

Where:

$D_{i}$ is the descriptor $i$ ( $i$ ranges from 1 to 3 ). A, B, C and E are linear regression coefficients. So using four experimental $\mathrm{pKa}$ values, we obtained a system of four equations with four unknowns (A, B, The descriptors [22] can be chosen using domain knowledge about the examined property (literature considerations), or the mathematical methods for the selection of descriptors can be applied. The reasons for the choice of the above quantum descriptors are mentioned below:

\section{Volume 4 Issue 12, December 2015}




\section{International Journal of Science and Research (IJSR) \\ ISSN (Online): 2319-7064}

Index Copernicus Value (2013): 6.14 | Impact Factor (2014): 5.611

- The HOMO energy is related to ionization energy and characterized the susceptibility of the molecule towards electrophiles attacks;

- The LUMO energy is related to electron affinity and indicates the susceptibility of the molecule to nucleophiles attacks;

- The energy gap $\Delta E$ is an important reactivity index. Large value of energy gap implies lower reactivity in chemical reactions.

- The dipole moment $\mu$ is the most often used quantity to describe the polarity of a molecule which is important for various physicochemical properties,

- Partial atomic charge $\delta$ which allows the prediction of relative acidity or reactivity by estimating the extent of charge delocalization based on molecular structure information.
So we have constructed five sets:

Set 2: $E_{\text {LUMO }} E_{\text {HOMO }} \Delta E$

Set 3: $E_{\text {LUMO }} E_{\text {HOMO }} \mu$

Set 4: $E_{\text {LUMO }} \Delta E_{o} \mu$

Set 5: $E_{\text {Howo }}, \Delta E_{s} \mu$

As it can be seen in our previous work [23], the best set is: $\left(E_{\text {HONO }}, \Delta E_{x} \mu\right)$. The mathematical relation for first and second dissociation constant is:

$$
p K a_{\mathrm{i}}=A_{\mathrm{i}} E_{\text {HOMO }}+B_{\mathrm{i}} \Delta E+C_{\mathrm{i}} \mu+E_{\mathrm{i}}
$$

Using three other carboxylic acids: salicylic acid, benzoic acid and lactic acid in the same conditions (three other $\mathrm{pKa}$ values) [23] we obtained the systems of four equations with four unknowns.

Table 6 gives the coefficients connecting $\mathrm{pKa}_{1}$ and $\mathrm{pKa} \mathrm{a}_{2}$ to the descriptors.

\section{Set 1: $\Delta E_{s} \mu_{v} \delta$}

Table 6: Computed values of coefficients relating $\mathrm{pKa}_{1}$ and $\mathrm{pKa}_{2}$ to the molecular descriptors at $\mathrm{T}=298 \mathrm{~K}$.

\begin{tabular}{|c|c|c|c|c|c|c|c|c|}
\hline Ethanol weight (\%) & $\mathrm{A}_{1}$ & $\mathrm{~A}_{2}$ & $\mathrm{~B}_{1}$ & $\mathrm{~B}_{2}$ & $\mathrm{C}_{1}$ & $\mathrm{C}_{2}$ & $\mathrm{E}_{1}$ & $\mathrm{E}_{2}$ \\
\hline 0 & 125.15 & 49.13 & 50.87 & 20.03 & -46.79 & -18.93 & 759.16 & 301.48 \\
\hline 16.3 & 146.65 & 65.36 & 59.44 & 26.45 & -54.98 & -25.17 & 890.72 & 401.19 \\
\hline 80 & 202.53 & 96.55 & 82.03 & 39.03 & -75.95 & -37.09 & 1231.13 & 592.99 \\
\hline
\end{tabular}

Figures4 gives the representations of experimental $\mathrm{pKa}$ versus computed ones.

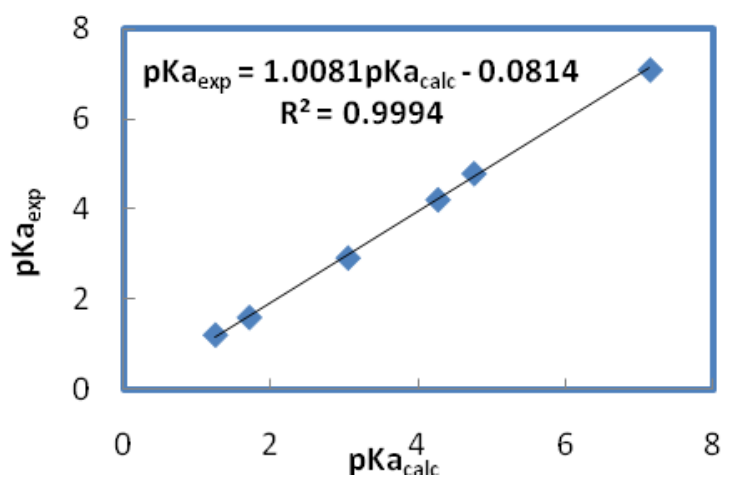

Figure 4: Experimental pKa values versus computed ones.

The representation yields a straight line with a correlation coefficient very close to unity. To express the consistency between experimental and calculated $\mathrm{pKa}$ values we have also calculated the root mean square errors using the relation below:

RMSE $=\sqrt{\sum_{i=1}^{N} \frac{\left|p K a_{\exp }^{i}-p K a_{c a i d}^{i}\right|^{2}}{N}}$

WherepK $a_{\exp }^{\mathrm{i}}$ and $p K a_{\text {calc }}^{\mathrm{i}}$ are respectively experimental and computed $\mathrm{pKa}$ values with the model. $\mathrm{N}$ denotes the number of data points. $\mathrm{N}=6$ and $\mathrm{RMSE}=0.082$ : this lower value indicates high correlation between experimental and theoretical values.

\section{Conclusions}

From the above results one can draw the following conclusions:

1) The first and second dissociation constant of oxalic acid are directly proportional to the square root of the ionic strength of the solution of water-ethanol solvent.
2) The first and the second dissociation constant $\mathrm{pKa}_{1}$ and $\mathrm{pKa}_{2}$ of the oxalic acid in water-ethanol solvent increases with increasing weight of ethanol.

3) The first dissociation constant $\mathrm{pKa}_{1}$ of oxalic acid decreases with increasing temperature, whereas we note the reverse behaviour with the second dissociation constant $\mathrm{pKa}_{2}$.

4) The sign of the standard free changes of first and second dissociation constants indicates spontaneous processes.

5) The sign of the obtained enthalpy changes indicates an exothermic process for the first dissociation process and an endothermic one for the second.

6) For both, first and second dissociation processes, the negative sign of entropy changes shows a trend of increasing order.

7) Experimental and theoretical results are in good agreement.

\section{References}

[1] S. A. Kristine, C. S. George, "Theoretical Calculations of acid dissociation constants: a review article", J. Annual Reports in Computational Chemistry, 6 (1), pp. 13-38, 2010.

[2] Y. H. Zhao, L. H. Yuan, L. S. Wang, "Quantative Structure- Activity Relationships of Organic Acids and Bases, " Bull. Environ. Contam. Toxicol., 57, pp. 242249, 1996.

[3] H. Rochester, "Acidity Functions," Academic Press: New York, 1971.

[4] L. P. Hammet, "Physical Organic Chemistry," McGraw-Hill: New York, 1940.

[5] W. Q Tong, G. Whitesell, „In Situ salt screening: a useful technique for discovery and performulation studies" Pharm. Dev. Technol., 3(2), pp. 215-223, 1998

[6] S. Babic, A. J. M. Horvat, D. M. Pavlovic, M. K. Macan,'Determination of $\mathrm{pKa}$ values of active 


\section{International Journal of Science and Research (IJSR) \\ ISSN (Online): 2319-7064}

Index Copernicus Value (2013): 6.14 | Impact Factor (2014): 5.611

pharmaceutical ingredients", Trends in Analytical Chemistry, 26 (11), pp.1043-1061, 2007.

[7] Markus, M. and T. Eichinger, "Determination of $\mathrm{pKa}$ values by Liquid Chromatography", Journal of Chromatographic science, 41, pp. 323-326, 2003.

[8] R. Haixia, W. Licheng, W. Xusheng, I. Xia, J. Shangxing, "Measurement of acid dissociation constant and Ionic mobilities of 3-nitro-tyrosine by capillary zone Electrophoresis", Journal of Pharm. And Biomedical Analysis, 77 pp. 83-87, 2013.

[9] D. ö Shivakumar, J. Williams, Y.Wu, W.Damm, J.Shelley, W.Sherman, "Prediction of Absolute Solvation Free Energies using Molecular Dynamics Free Energy Perturbation and the OPLS Force Field", J. Chem. Theory Comput., 6, pp. 1509-1519, 2010.

[10]J. R. Pliego, "Thermodynamic cycles and the calculation of pKa", Chem. Phys. Lett., 367 pp.145-149, 2003.

[11]B. R. Bickmore, C. J. Tadanier, K.M.Rosso, W. D.Monn, D. L. Eggett, "Geochim. Cosmochim. Acta", 68 pp. 2025-2042, 2004.

[12]R. R. da Silva, T. C. Ramalho, J. M. Santos, J. D. Figueroa Villar, J. Phys. Chem. A 110 (3) pp.10311040, 2006.

[13]A. Habibi Yangjeh, M.Danandeh Jenagharad, M.Nooshyar, "Application of artificial neural networks for predicting the aqueous acidity of various phenols using QSAR” J. Mol. Model. 12(3)pp. 338- 347, 2006.

[14] M. D.Liptak, G. C. Shields, " Comparison of density functional theory predictions of gas-phase deprotonation data", Int. J. Quantum Chem., 105 (6) pp. 580-587, 2005.

[15] T. Puzyn, J. Leszczynski, M. T. D. Cronin, " Recent Advances in QSAR Studies", Springer, New York, pp. 3-11, 2010.

[16] R. M. Kettler, "Dissociation constant of oxalic acid in Aqueous Sodium chloride and Sodium Trifluorométhanesulfonate Media to $175^{\circ} \mathrm{C}$ ", J. Chem. Eng., 43, pp. 337-350, 1998.

[17]R. G. Bates, "Practical measurement of $\mathrm{pH}$ in amphiprotic and mixed solvents", International Union of Pure and Applied Chemistry, National Bureau of Standards, Washington D.C., U.S.A., 18(3) pp. 420425, 1969.

[18]K. J. Box, G. Völgyi, R. Ruiz, J. E. Comer, K. Takács-Novák, E. Bosch et al., "Physicochemical properties of a new multicomponent cosolvent system for the $\mathrm{pK}_{\mathrm{a}}$ determination of poorly soluble pharmaceutical compounds", Helvetica Chimica Acta, 9, pp. 1538-1553, 2007.

[19]N. M. Singh, R. Lalnuntluanga, Lalzawnpuia, "Evaluation of association constant and thermodynamic parameters of $\left[\mathrm{Cu}(\mathrm{Me}-\mathrm{AAUH})_{2}\right] \mathrm{Cl}_{2}$ complexes in aqueous medium", Der Chemica Sinica, 4(4) p.82-86, 2013.

[20]L. I. Song, M. Paleologon, and W. C. Purdy, "Determination of the acidity constants of chlorinated phenolic compounds by liquid chromatography, " J. Chromotogra. Sci., 29, pp. 66-69, 1991.

[21] Saeeduddin and A. W. K. Khanzada, "Thermodynamic dissociation constant studies of caffeine at different temperatures and in organic water solvent mixture,"
Pakistan J. Pharmaceutical Sciences, 17(1), pp. 83-87, 2004.

[22] K. C.Gross, P. G.Seybold, "Substituent effects on the physical properties and pKa of phenol" Int.J. Quantum Chem., 85, pp. 569-579, 2001.

[23] D. C.Assouma, K. K. E. Kouassi, P. M. Niamien, K. H. Aka., "Acid dissociation constant $\mathrm{pKa}$ of some carboxylic acids: correlation between experimental and theoretical values using density functional theory and QSPR” Aust. J. Basic \& Appl. Sci., 9(31) pp.110-118, 2015. 